\title{
WET ETCHING \& UNIFORM WAFER-LEVEL THINNING OF BULK PIEZOELETRIC CERAMICS ON SILICON
}

\author{
Ethem Erkan Aktakka ${ }^{*}$ Rebecca L. Peterson, and Khalil Najafi \\ Center for Wireless Integrated MicroSensing and Systems (WIMS ${ }^{2}$ ) \\ University of Michigan, Ann Arbor, MI, USA
}

\section{ABSTRACT}

This paper presents new micro-fabrication tools and material/process characterization for wafer-level lapping and wetetch patterning of bulk PZT on silicon. The process enables precise control over final film thickness $(5-100 \mu \mathrm{m})$ with high wafer-level uniformity $( \pm 0.5 \mu \mathrm{m})$, and the lapping-rate $(10-30 \mu \mathrm{m} / \mathrm{min})$ and surface roughness $(43 \mathrm{~nm})$ are characterized. Additionally, surface micro-machining of suspended PZT structures is demonstrated by bonding and thinning over pre-patterned silicon features. Finally, a new wet-etching process is developed for low-undercut $(0.6: 1)$ patterning of $>5 \mu \mathrm{m}$ thick PZT films, and $\mathrm{d}_{33 \text {-EFF }}$ piezoelectric strain coefficients on thinned and patterned bulk PZT-5A and $5 \mathrm{H}$ films are measured as 140 and $311 \mathrm{pm} / \mathrm{V}$, respectively.

\section{INTRODUCTION}

Recently, we introduced a micro-fabrication technology for integration of bulk PZT-5A substrates on silicon by solder bonding and thinning, to realize mm-scale diaphragm actuators [1] and energy harvesters [2]. In this paper, we report new microfabrication methods to achieve precise PZT film thickness with excellent wafer-level uniformity and reduced minimum film thickness $(\sim 5 \mu \mathrm{m})$ in a reliable process. We also report here surface micro-machining of PZT diaphragms, wet-etching of thick PZT films, and integration of PZT-5H for higher piezoelectric response than PZT-5A (Fig. 1). These processes are critical to enable batchmode fabrication of miniaturized and high-performance microspeakers, microphones, microfluidic devices, and complex-shape actuators. The microfabrication techniques introduced here offer increased reliability, fabrication flexibility, and higher material quality over existing piezoelectric film deposition methods.

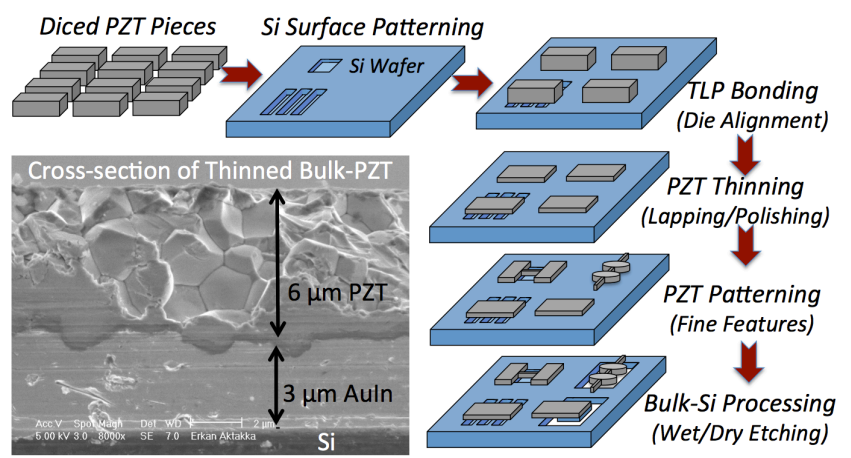

Figure 1: Bulk-PZT on Si process and SEM image of final PZT film.

\section{UNIFORM WAFER-LEVEL THINNING}

Minimizing wafer-level variation of thinned-PZT thickness is critical for batch-mode MEMS fabrication. It can be as high as $\pm 18 \mu \mathrm{m}$ on a typical wafer, often due to increased lapping rates near the wafer edge. A new method is developed to improve waferscale thinning uniformity and to precisely define the final PZT thickness, by leveraging the silicon-wafer surface as a thinningstop layer (Fig. 2). A $0.5 \mu \mathrm{m}$ thermal-oxide layer enhances surface hardness, and the lapping rate decreases very effectively $(\sim 100 \times)$ upon leveling of PZT with the $\mathrm{Si} / \mathrm{SiO}_{2}$ surface (Fig. 3). Highly uniform film thickness $( \pm 0.5 \mu \mathrm{m})$ is obtained across 4 -inch wafers.
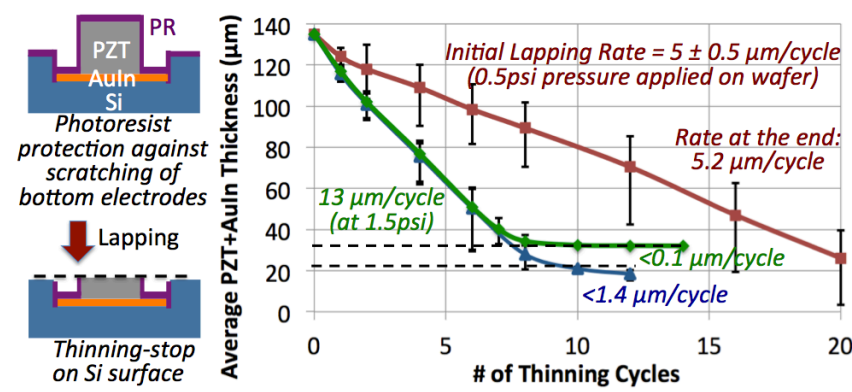

Test Stop Height of Decrease in lapping |Wafer-level thickness uniformity Wafer layer stop layer rate at the stop layer Max Deviation Standard Dev.

\begin{tabular}{|c|c|c|c|c|c|}
\hline & & & & & \\
\hline $\mathbf{\square} 1$ & N/A & - & - & $+/-17.2 \mu \mathrm{m}$ & $11.8 \mu \mathrm{m}$ \\
\hline$\Delta 2$ & $\mathrm{Si}$ & $22.5 \mu \mathrm{m}$ & $91.3 \%$ & $+/-1.8 \mu \mathrm{m}$ & $1.1 \mu \mathrm{m}$ \\
\hline
\end{tabular}

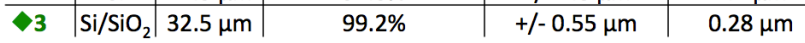

Figure 2: Change in the lapping rates when stop-layer is reached.

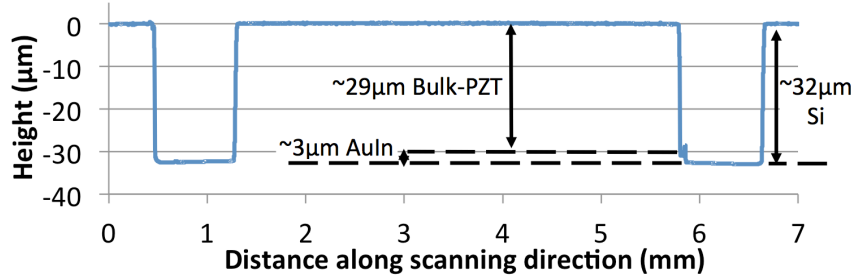

Figure 3: Flatness and thickness profile of a thinned-PZT die on Si.

For many applications, surface roughness of the final film is also a critical parameter. The average roughness on $20-\mu \mathrm{m}$ thick lapped/polished PZT films is characterized to be $43 \mathrm{~nm}$, which is acceptable for most MEMS and can be improved further by extending the polishing period (Fig. 4).
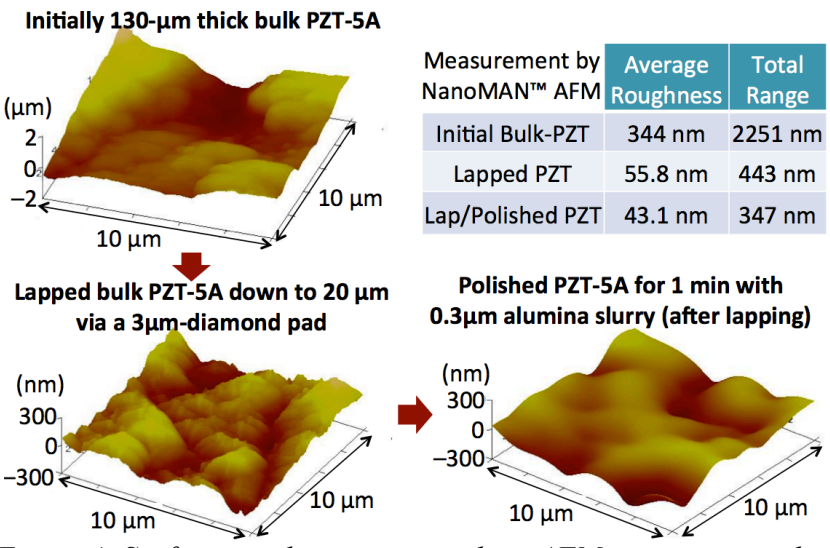

Polished PZT-5A for 1 min with $0.3 \mu \mathrm{m}$ alumina slurry (after lapping)

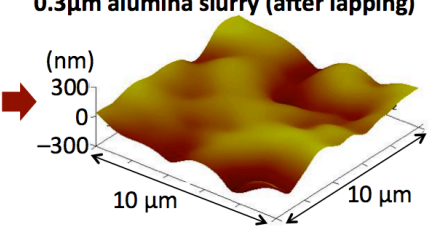

Figure 4: Surface roughness measured via AFM in tapping-mode.

For device-release purposes, PZT bonding/thinning over prepatterned silicon features is demonstrated as an alternative to expensive and time-consuming backside through-wafer etching. Suspended structures with up to 1:40 thickness:diameter ratio are fabricated, which can be used for diaphragm actuation in acoustic, ultrasonic and microfluidic applications (Fig. 5-6). This unique surface micro-machining capability also facilitates easier packaging, and is not attainable with other piezoelectric-film deposition methods, where a flat deposition surface is required. 

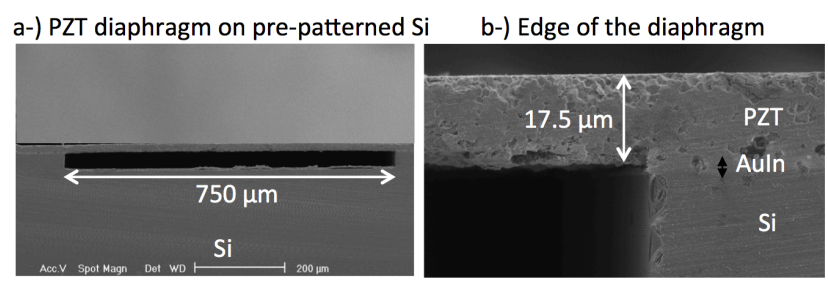

Figure 5: Suspended PZT layer bonded and thinned over Si cavity. a-) Bonding and lapping of PZT on pre-patterned Si features
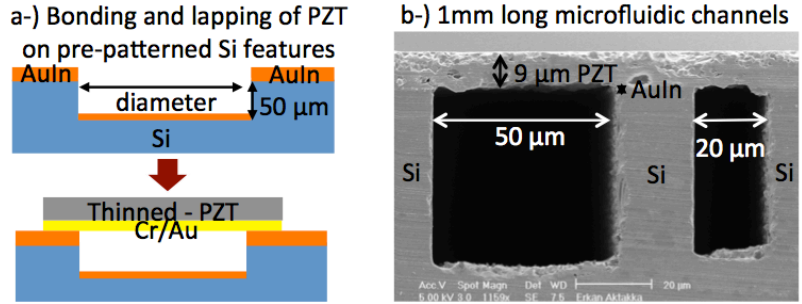

c-) Measured min. PZT thickness obtained for different membrane sizes

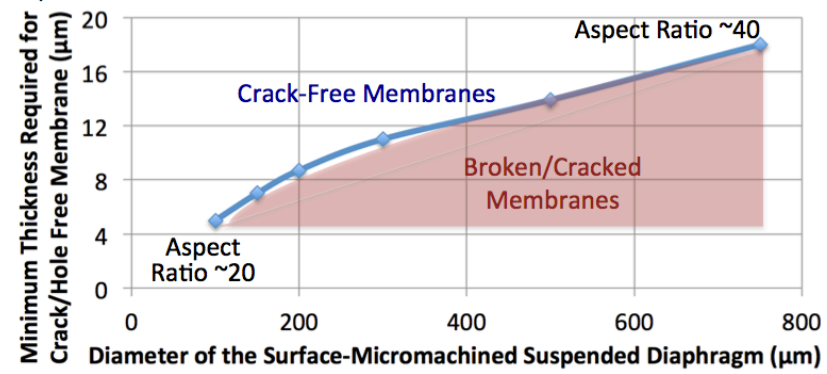

Figure 6: Minimum PZT thickness obtained versus diaphragm size.

\section{LOW-UNDERCUT WET-ETCHING}

Wet-etching of PZT structures is highly desirable, since it provides a cost-effective, high-throughput process, and enables lithographically-defined features. However, previous studies mostly focused on sol-gel spin-coated 1-2 $\mu \mathrm{m}$ thick films, with high-undercut ratios of $1.5: 1$ to $5: 1$ [3-6]. For etching through the complex composition of $>5 \mu \mathrm{m}$ thick PZT films, using the right mix of chemical reagents is critical, since residues due to reaction by-products cause unreliable etch rates and increased undercut. Here, a new mixture is utilized, $\mathrm{BHF}: \mathrm{HNO}_{3}(67 \%): \mathrm{HCl}(38 \%)$ with 2:2:1 ratio, which is $14 \times$ diluted by $\mathrm{DI}-\mathrm{H}_{2} \mathrm{O}$ to achieve a controllable etch rate and prevent photoresist-mask delamination. The solution is heated to $40^{\circ} \mathrm{C}$ in order to increase etching efficiency and obtain a better undercut profile. The etch process is expected to follow the below equations, where $\mathrm{PbClF}$ residue is converted into $\mathrm{PbCl}_{2}$, which has a higher solubility in water [7].

$$
\begin{aligned}
\mathrm{Pb}(\mathrm{Ti}, \mathrm{Zr}) \mathrm{O}_{3}(\mathrm{~s})+\mathrm{HCl}(\mathrm{aq}) & +\mathrm{HF}(\mathrm{aq}) \rightarrow\left[\mathrm{TiF}_{6}\right]^{2-}(a q)+\left[\mathrm{ZrF}_{6}\right]^{2-}(a q) \\
+\left[\mathrm{PbCl}_{4}\right]^{2-}(a q)+\mathrm{PbClF}(\mathrm{s})+\mathrm{H}_{2} \mathrm{O}(\mathrm{l}) & (1) \\
\mathrm{PbClF}(\mathrm{s})+\mathrm{HNO}_{3}(a q) \rightarrow \mathrm{PbCl}_{2}(\mathrm{~s}) & +\mathrm{Pb}^{2+}(a q) \\
& +\mathrm{NO}_{3}^{-}(a q)+\mathrm{HF}(a q)
\end{aligned}
$$

To minimize undercut, multiple cycles of lithography followed by wet-etching are used (Fig. 7). Only a portion of the total thickness is etched in each cycle (etch rate $2-3 \mu \mathrm{m} / \mathrm{min}$ ), followed by ultrasonic cleaning. Then the photoresist mask is removed and a new photoresist layer is added to coat the previously-created undercut region. Patterning of $18 \mu \mathrm{m}$ thick PZT in two cycles yields an undercut ratio of 0.6:1 (Fig. 8).

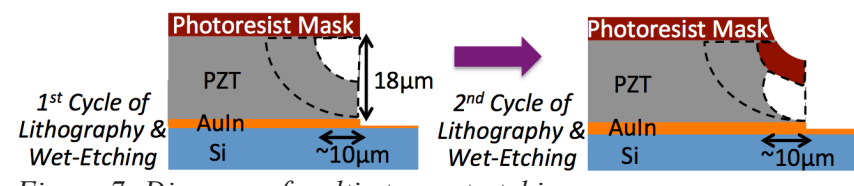

Figure 7: Diagram of multi-step wet-etching process.

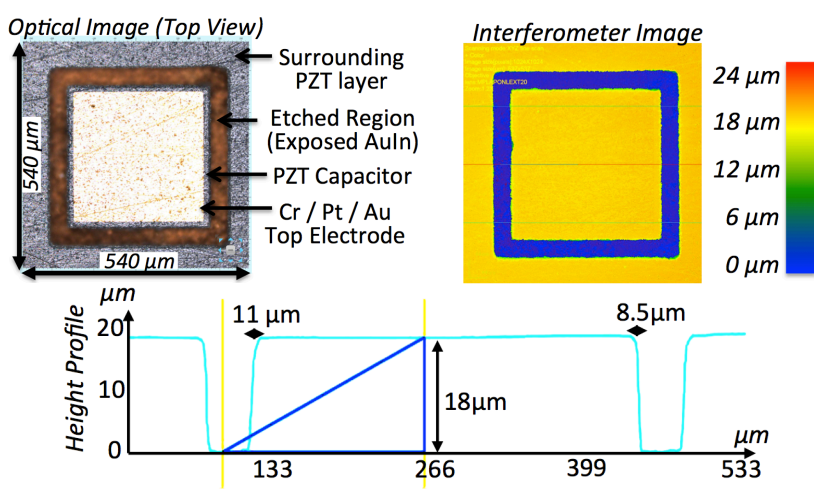

Figure 8: Wet-etched $18 \mu \mathrm{m}$ thick PZT layer with 0.6:1 undercut. MEASURED PIEZOELECTRIC PROPERTIES

Preservation of bulk piezoelectric properties in the final bonded/thinned/patterned $\mathrm{PZT}-5 \mathrm{~A} / 5 \mathrm{H}$ films is confirmed via piezo-response force microscopy (Fig. 9). The $d_{33}$ values calculated from measured $\mathrm{d}_{33 \text { eff }}$ [8] are close to the values in vendor datasheets for the bulk materials (Table 1), and are notably higher than values of existing thin-film-deposited piezoelectrics.

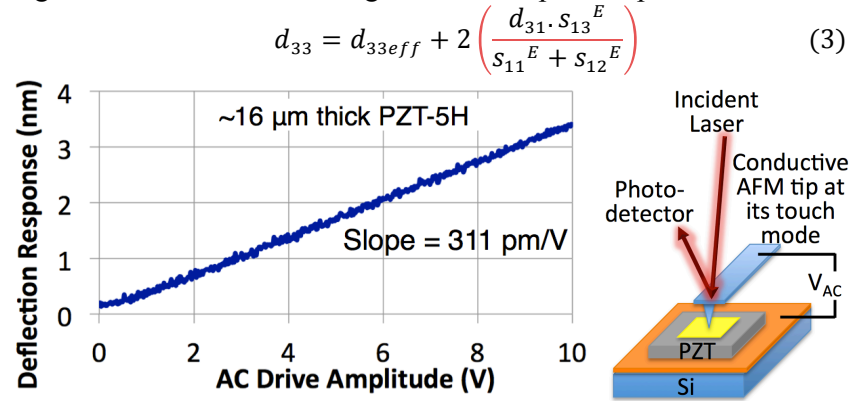

Figure 9: Piezoelectric response measured on $300 \mu \mathrm{m} \times 300 \mu \mathrm{m}$, $16 \mu \mathrm{m}$ thick PZT5A/5H capacitors via piezo-force-microscopy.

Table 1: Measured longitudinal piezoelectric strain coefficients on $16 \mu \mathrm{m}$ thick PZT-5A/5H films on Si without any repolarization.

\begin{tabular}{c|c|c|c} 
& $\begin{array}{c}\mathrm{d}_{33-E F F} \\
\text { (Measured) }\end{array}$ & $\begin{array}{c}\mathrm{d}_{33} \\
\text { (Calculated) }\end{array}$ & $\begin{array}{c}\mathrm{d}_{33} \\
\text { (Vendor Datasheet) }\end{array}$ \\
\hline PZT-5A & $140 \mathrm{pm} / \mathrm{V}$ & $398 \mathrm{pm} / \mathrm{V}$ & $390 \mathrm{pm} / \mathrm{V}$ \\
\hline PZT-5H & $311 \mathrm{pm} / \mathrm{V}$ & $772 \mathrm{pm} / \mathrm{V}$ & $650 \mathrm{pm} / \mathrm{V}$
\end{tabular}

\section{ACKNOWLEDGEMENT}

This work is partially supported by DARPA awards, Hybrid Insect MEMS \#N66001-07-1-2006 and PASCAL \#W31P4Q-12-1-0002.

\section{REFERENCES}

[1] E.E. Aktakka, H. Kim, K. Najafi, Transducers'09, (2009), pp. 849-852.

[2] E.E. Aktakka, R.L. Peterson, K. Najafi, Transducers'11, (2011), pp. 1649-1652.

[3] L.-P. Wang, R. Wolf, Q. Zhou, S. Trolier-McKinstry, R. J. Davis, MRS Symp., Vol. 657 (2001), pp. EE5.39.1- EE5.39.6.

[4] Y.B. Jeon, C.W. Wong, S.-G. Kim, Journal of Electroceramics, 13, 509 (2004).

[5] C. Cai, J. Huang, Y. Zhai, W. Ma, W. Liu, Chinese Optics Letters, 8, 210 (2010).

[6] L. Che, E. Halvorsen, X. Chen, Journal of Micromechmanics and Microengineering, 21, 105008 (2011).

[7] K. Zheng, J. Lu, J. Chu, Jpn. J. Appl. Phys., 43, 3934 (2004).

[8] K. Prume, P. Muralt, F. Calame, T. Schmitz-Kempen, S. Tiedke, IEEE Trans. UFFC, 54, 8 (2007).

\section{CONTACT}

* E. E. Aktakka, tel: +1-734-272-3170; aktakka@umich.edu K. Najafi, tel: +1-734-763-6650; najafi@umich.edu 